Таня Попович

Университет в Белграде

tanja.popovic19@gmail.com

\title{
Функция и семантика удвоенных форм в повестях Н.В. Гоголя Старосветские помещики, Страшная месть и Нос
}

\begin{abstract}
Popović Tanja, Funkcia i semantika udvoennzh form v povestjah N.V. Gogol'a Starosvetskie pomeščiki, Strašnaja mest' $i$ Nos (Function and Meaning of Double Forms in Gogol's Stories The Old World Landowners, A Terrible Vengeance and The Nose). "Poznańskie Studia Slawistyczne" 13. Poznań 2017. Publishing House of the Poznań Society for the Advancement of the Arts and Sciences, pp. 67-80. ISSN 2084-3011.

In this study, we are trying to connect the J. Tynjanov's theory of the constructive principle of the genre with the M.M. Bahtin's theory of genre memory, through the analysis of Gogol's stories Old World Landowners materials A Terrible Vengeance and The Nose. This research is primarily focused on the meaning and the function of their double structure. Double structure principle reflects in levels of genre, in levels of the speech, in levels of chronotope, as well as in literary heroes motivation. Doubling reality and characters that are in the narrative world of Gogol is often transmitted using a mirror, a Double, a dream or a vision, showing, in fact, the inconvenience that every man feels when confronted not only with his „I', but also when he attempts to explain himself through Others, see himself in someone else's soul. A symbolic expression of this internal state occurs in a similar manner, using similar concepts and ideas, double structures which it is advisable to bind together the idea and its realization.
\end{abstract}

KEYwords: function; genre; double structure; constructive principle; genre memory; chronotope; Gogol

В своих знаменитых теоретических работах, „Литературный факт” и „О литературной эволюции”, Юрий Тынянов выдвигает вопрос о функции и конструктивном принципе литературных жанров (Тынянов, 1977, 255-281). Рассматривая системность литературного ряда и литературного произведения, он особенно подчеркивает проблемы соотнесенности и взаимодействия отдельных элементов: каждого ряда (литературы, искусства, быта и т.д.), формы (жанра) и произведения. Изучение изменчивости данных элементов со своей стороны связано с их конструктивной функцией. Каждая функция 
ищет свои формы, при чем и эволюция форм вызывает изменение самой функции. С такой точки зрения, жанр не надо считать статическим явлением. Жанр не постоянная и не неподвижная система. Иногда и фрагмент какого-то жанра может быть осознан как жанр. Более того, эволюцию жанра характеризует смешение разнообразных приёмов, т.е. конструктивных принципов. Суть новой конструкции лежит в новом использовании старых приёмов, в их новом конструктивном значении. Своеобразие литературного произведения - в приложении конструктивного фактора к материалу, в оформлении, т.е. в деформации материала. Материал у Тынянова, рассматривается как „подчиненный элемент формы за счет выдвинутых конструктивных” (Тынянов, 1977, 261).

Материал литературного произведения, в теориях русских формалистов, как правило, - речевой, словесный, он одновременно относится и к быту, и к литературной традиции. Быт соотнесен с литературой прежде всего своей речевой стороной. Использование литературной традиции в новых произведениях гораздо сложнее, потому что в том смысле материалом можно считать почти всё - приёмы, жанры, образы, фабулы, мотивы, мелкие речевые формы (паремии), цитаты и т.д. Важно подчеркнуть, что каждый из перечисленных элементов тоже рассматривается в свете системности, т.е. с точки зрения их взаимодействий.

Понимание литературной эволюции у Тынянова, а также и у ученых, опирающихся на его теоретические предпосылки (Б.М. Эйхенбаума, Р.О. Якобсона, чешских структуралистов, Я. Мукаржовского и др.), в первую очередь сосредоточено на вопросах формы, ее конструкции и функции, на системности и взаимодействиях. Литературный жанр рассматривается и интерпретируется преимущественно с точки зрения процесса его формирования, часто без учёта внутренной и внешней идейностях художественного произведения.

Исследования жанровых истоков по другому толкуются в бахтинских теориях исторической поэтики. В книге „Проблемы поэтики Достоевского” М.М. Бахтин сформулировал понятие память жанра, которое относится к концепции жанра как „зоны и поля ценностного восприятия и изображения мира" (Бахтин, 1963, 117). Более того, именно жанры являются главными героями истории 
литературы, обеспечивающими преемственность ее развития. Жанр, по Бахтину, „живет настоящим, но всегда помнит свое прошлое, свое начало. Жанр - представитель творческой памяти в процессе литературного развития" (Бахтин, 1963, 122). Память жанра раскрывается в целостной, но двоякой соотнесенности: 1) как относящаяся к собственно жанру и синонимичная понятиям „логика жанра” и „жанровая сущность”; 2) как относящаяся к жизни литературы „объективная форма” сохранения ее традиций. Память жанра подразумевает ,реализацию в большом времени изначально заложенных в жанре возможностей смысла - того, чем было «чревато» его прошлое; при этом чем более высокого и сложного уровня достиг жанр, тем ярче проступают в нем черты архаики, определявшие его в момент зарождения, т.е. «тем он лучше и полнее помнит свое прошлое" (Бахтин, 1963, 139).

Но, как уже отмечено С.Г. Бочаровым, Бахтин понятие памяти жанра создал на своеобразном парадоксе, так как речь идет не о субъективной памяти автора, а о объективной памяти самого жанра, в котором он работал (Бочаров, 2012, 9) ${ }^{1}$. Бочаров также указывает на бахтинские черновики, в которых ученый продолжает искать суть категории жанра, говоря о „культурно-исторической телепатии”, т.е. о передачи и воспроизведении

через пространства и времена очень сложных мыслительных и художественных комплексов без всякого уследимого реального контакта. Кончик, краюшек такого органического единства достаточен, чтобы развернуть и воспроизвести сложное органическое целое, поскольку в этом ничтожном клочке сохранились потенции целого и лазейки структуры (...), (Бахтин, 2002/6, 323).

В данном исследовании, мы попробуем соединить теоретические предпосылки о конструктивном принципе жанра с теорией памяти жанра, на материалах повести Гоголя Старосветские помещики

${ }^{1}$ С.Г. Бочаров рассматривает и другие понятия, касающиеся жанровой изменчивости или генетической памяти литературы, такие как, „внутренняя форма” Л.В. Пумпянского, „резонанс” В.Н. Топорова, ,литературные примопонимания” А.Л. Бема, психоаналитические теории „творческой памяти” и бессознательного К.Г. Юнга и Р. Барта, интертекстуальность в теориях Ю. Кристевой, Р. Барта, Ж. Дерриды, У. Эка (Бочаров, 2012, 7-44). 
(сборник Миргород, 1835), Страшная месть (сборник Вечера на хуторе близ Диканьки, 1832) и Нос (журнал Современник, 1836), имея ввиду прежде всего их двойную структуру, уже давно отмеченную главным признаком художественного мира русского писателя (Белый, 1934; Ремизов, 1954; Günther, 1968; Манн, 1996; Лотман, 1988; Вайскопф, 2002).

Повесть Гоголя Старосветские помещики открывается картиной буколической жизни в малорусской провинции. Изображение семейного счастья и гармонии природы создано на почве литературной и художественной традиций идиллии, при чем героев повести, Афанасия Ивановича и Пульхерию Ивановну Товстогубых, „двух старичков прошедшего века”, автор сравнивает с героями античного мифа Филемоном и Бавкидой: „Если бы я был живописец и хотел изобразить на полотне Филемона и Бавкиду, я бы никогда не избрал другого оригинала, кроме их" (Гоголь, 1976/2, 7-29)². В начале повести отчетливо обозначены основные рамки её художественного мира: он соткан из двойной ткани разных исторических времён и литературных пространств, а сама действительность в повествовании изображена неподвижно, как в живописи. Мир повести представлен извне, с точки зрения повествователя: „Я отсюд $a^{3}$ вижу низенький домик с галерею из маленьких почернелых деревянных столбиков". Картина буколической жизни является ему как бы во сне (,„ы их видел только в блестящем, сверкающем сновидении”), или как воспоминание о прошлом („Их лица мне представляются и теперь иногда в шуме и толпе среди модных фраков, и тогда вдруг на меня находит полусон и мерещится былое").

Итак, повествовательный дискурс совсем не реалистичен. Здесь речь идет о мнимой действительности, созданной на почве традиционных, исторических и мифологических представлений. Внешний мир старосветских помещиков преображён внутренними впечатлениями повествователя и, тем самым, он представлен с особой идеологической точки зрения. Именно с этой точки зрения вводится читатель во внутреннюю картину повести, насыщенную значениями, заимствованными из античного мифа и русского прошлого.

\footnotetext{
2 Здесь и далее повесть Гоголя цитируется по этому изданию.

3 Здесь и далее курсив в цитатах мой - Т.П.
} 
Сравнивая фабулу античного мифа о Филемоне и Бавкиде с фабулой гоголевской повести, нетрудно заметить, что они похожи. Их герои - пожилые, гостеприимные люди, очень преданные друг к другу. Дом их отличается изобилием, а сад - роскошной вегетацией, как в любом ландшафте, характерном для жанра идиллии. Но развёртывание сюжета у Гоголя идет по другому сценарию. В отличие от стариков из древнего предания, Пульхерии Ивановне и Афанасию Ивановичу не удалось умереть одновременно - первой умерла Пульхерия Ивановна, а через пят лет упокоился и Афанасий Иванович. После смерти „старосветских помещиков” изменилась вся жизнь: хотя «всё было по-прежнему», смотритель-повествователь ,заметил во всем какой-то странный беспорядок”. „Домик барский уже сделался вовсе пуст", а окончательное разрушение спокойной, счастливой и гармоничной жизни обозначено появлением „дальнего родственника”, наследника, „страшного реформатора”, который приехал „неизвестно откуда". Таким образом, первая буколическая часть повести к концу превращается в свою противоположность: вместо богатства там - пустота, изобилие домашней пищи сменили ,разные большие произведения, продающиеся оптом" на ярмарках; некогда уютный домик сейчас „развалился вовсе”. Новый хозяин „решился... ввести во всем порядок” в результате чего „имение через шесть месяцев взято было в опеку".

Как уже сказано, начало повести во всём создано по законам буколики. Покой ее жителей и гармония природы перенесены в древние времена. Кроме того, описание прошедшей жизни даётся статично, как будто речь о застывшей картине. Рассказчик даже говорит о себе как о живописце, а о семейном счастье Пульхерии Ивановны и Афанасия Ивановича как о художественном произведении, перенесенном на полотно. Отсюда фон повествования отличается древностью и неподвижностью ${ }^{4}$ В противоположность этому, конец повести изображает

${ }^{4} \mathrm{Cp}$. замечание М. Виролайнен: „Характеры героев повести статичны, в них все задано изначально, вместо обнаружения нового происходит раскрытие от века им присущего - но раскрытие на все большей и большей глубине. Неподвижность, неизменность их способа жизни не однократно подчеркнута: действия героев происходят «всегда», «обыкновенно» - или «никогда» не происходят”. (Виролайнен, 2003, 312-313). 
разрушение первоначального идиллического мира. Признаками, а, можно добавить, и причинами уничтожения общечеловеческого счастья и доброты явились чужие вещи (,английский серп”, произведения, продававшиеся на ярмарках), чуждые повествованию персонажи, как наследник-реформатор и даже животные (кошка Пульхерии Ивановны) - всё, приходящее извне, из-за рамок этого неподвижного, ограниченного мира. Они проникли в буколическую жизнь из чужого мира: реформатор „неизвестно откуда”, а кошка из „дикого, мрачного леса". Они противопоставлены не только прежним обитателям старосветского поместья, но их внутреннему буколическому миру.

В повести Старосветские помещиики, как и в других произведениях Гоголя, каждая мелочь таит в себе множество различных значений. Многие исследователи его творчества указывали, что гоголевское художественное пространство, как правило, подразумевает существование двух миров - реального и потустороннего (Анненский, 1979; Белый, 1934; Nabokov, 1944; Манн, 1996; Лотман, 1988; Вайскопф, 2002 и др.). Поэтому важно отметить, какими признаками наделен каждый из миров, проникнуть в их нравственный и идеологический смысл. Повествование у Гоголя часто похоже на театральную постановку, причем персонажи, аксессуары и другие детали сопряжены в каждой отдельной сцене с определенными смысловыми тенденциями. Именно с этой точки зрения упоминание „цивилизации”, „ярмарки”, „реформы” или „крыши с английским серпом” в конце произведения, можно толковать не только как описание атмосферы новой, современной жизни, но и как авторские комментарии, и как своеобразный интертекстуальный диалог. Гоголевским прототекстом в начале повести были античный сюжет (овидиевский миф о Филемоне и Бавкиде), ровно как и античный жанр (идиллия); в конце повести гиппотекстом стали некоторые идеи, характерные для современной ему общественной мысли.

Форма повести сначала преображается по формальным и семантическим законам идиллии. Возрождение античного жанра, однако, проходит не с помощью повествовательных приёмов, а благодаря приемам изобразительного искусства. Таким образом, один и тот же сюжет воплощен средствами разных художественных рядов. Как утверждает Ю. Лотман, 
пространство в художественном произведении моделируют разные связи картины мира: временные, социальные, этические. Это происходить потому, что в той или иной модели мира категория пространства сложно слита с теми или иными понятиями, существующими в нашей картине мира как раздельные или противоположные (Лотман, 1988, 252).

Изображение действительности повести Старосветские помещи$\kappa u$, хотя и представлено в литературном жанре, оформлено по законам изобразительного искусства. Живописное изображение потом превращается в повествование, что несомненно сделано с определёнными идеологическими претензиями. Таким образом, диалог с античной традицией идиллии оказался положительным, а диалог со „страшными реформами”, происходящими „неизвестно откуда”, который получил форму мелодрамы, превратился в своеобразную полемику с современными культурными тенденциями.

Если повесть Старосветские помещиики оформлена на одновременном возрождении и деформации жанра идиллии ${ }^{5}$, то повесть Страшная месть свой внутренний мир создаёт на почве героических и мифологических жанров. В Старосветских помещиках реализованная память идиллии, не только в формальном, но и в идеологическом смысле, так как в Страшной мести полностью реализованная память жанра героической поэмы („песни бандуриста”). Как уже отмечено, эволюция отдельных форм вызывает изменение их жанровой функции, при чем система литературного ряда в непрерывной соотнесенности с другими рядами - с живописью, бытом или театральным искусством - творит двуплановую структуру художественного мира повести. Речевая динамика повествования здесь противоречит неподвижной внутренней действительности, которую характеризует неподвижность потусторонних времени и пространства.

Начало и конец (эпилог) в Страшной мести, как впрочем и в Старосветских помещиках, создают внешнюю, рамочную композицию повести: „золотое время”, „времена казацкой славы” в ее начале, превращается в ее конце в свою противоположность. Заметим что, внешняя, двойная структура формы соответствует двойному,

${ }^{5}$ В.В. Гиппиус считает, что здесь речь идет о „пародии на идиллию“ (Гиппиус, 1966, 74). 
внутреннему миру ее повествования. События прошлого времени отражаются своей неподвижностью в настоящем времени (клятва Ивана не позволяет изменить судьбы потомкам грешника Петро). Неподвижное пространство настоящей реальности („конец Киева”, „хутор между двумя горами”, „тихий свет Днепра”) деформировано (и объяснено) потусторонним видением Данила и снами Катерины („чужая земля”, „синий лес”, „черный старый замок”, „Днепр, будто вылит из стекла, будто голубая зеркальная дорога") (Гоголь, 1976/1, 139-176) Двойной художественный мир подразумевает двойных героев - Петро и Ивана из прошлого времени, и казака Данила, и его тестя-колдуна из настоящего. В гоголеведении уже отмечено, что основной прием изображения его „неопределенного рисунка” и персонажей лежит либо в „системе отрицаний” (Белый, 1934, 57), либо в „системе исключений” (Манн, 1996, 40). Используя термин русских формалистов, заметим, что формообразующей доминантой данной повести являются принципы перевернутости и отрицания, в результате которых художественный мир в конце преображен в пустоту (ср. „пустой барский домик” в конце Старосветских помещиков и „пустой хутор”, „пустой мир” в конце Страшной мести).

Повесть Нос также целиком создана на принципе двойственности, перевернутости и отрицания. Михаил Вайскопф в очень убедительном анализе данной повести эту двойственность и перевернутость определяет понятием зеркальности, добавляя, что именно зеркальность представляет основной структурный признак поэтики Гоголя. Более того, М. Вайскопф выделяет следующие аспекты зеркальности в гоголевской поэтике: 1) полную адекватность идеи (сущности) и ее образного выражения; 2) любую организующую идею как любой конструктивный принцип гоголевской поэтики, т.е. идею отображения понятия в образе, которая получает у Гоголя свое предметно-пространственное выражение - непосредственно в образе зеркала; 3) поскольку неизбежно возникает антиномия между статикой заданной идеи конкретного образа или произведения в его целом и сюжетной динамикой образа или повествования, проблема реализации идеи интерпретируется как вопрос о соотношении статических, „рамочных”

\footnotetext{
${ }^{6}$ Здесь и далее повесть Гоголя цитируется по этому изданию.
} 
форм ее фиксации с динамическими формами ее становления в сюжете, - прежде всего в плане непосредственного хронотопического воплощения; 4) диалектическое становление идеи, которая динамизирует и деформирует ее предметно-пространственную объективность; таким образом создается эффект нарочитой неадекватности или асимметрии заданной изначально идеи и ее предметного отражения в образе (Вайскопф, 2003, 51-52).

Когда речь идет о жанровых корнях повести Нос, можно сказать, что ее фабула возникла из повествовательного развертывания мелких речевых форм: „черт возьми”, „черт знает”, „показать кому нос”, „не видеть дальше своего носа”, „водить за нос кого-либо”, „повесить нос”, „натянуть кому-либо нос” и т.д. (Виноградов, 1963, 180-184). Гоголь в своей повести одновременно реализует и прямое, и переносное значение данных фразеологизмов, создавая таким образом не только эффект неадекватности или асимметрии идеи (абсурда), но и двуплановость пространства и времени.

Итак, сюжет Носа строится на непрерывной игре с зеркалами, которыми управляет сам черт (Мережковский, 1906; Белый, 1934; Nabokov, 1944; Јовановић, 1995 и др.).. Уже в названии повести мы видим обратный порядок: если прочитать с конца, как палиндром, то получится слово „сон”. Что речь идёт о сне, можно догадаться и по дате в начале и конце повести: „необыкновенно странное происшествие" начинается 25 марта, а заканчивается, безо всякого объяснения, 7 апреля. Тринадцать дней, „чёртова дюжина”, соответствуют разнице между григорианским и юлианским календарём ${ }^{7}$. Поэтому художественное время повести можно считать и „нулевым”, несуществующим, так как изображённые события происходят вне реальной действительности, во сне или в зеркале. В пользу этого говорят и практически одинаковые сцены, обрамляющие произведение: в начале повести (25 марта) главный герой после пробуждения видит в зеркале своё лицо без носа, а в конце (7 апреля) - с носом.

${ }^{7} 25$ марта/7 апреля по церковному календарю христиан отмечается Благовещение Пресвятой Богородицы. Если иметь в виду интерпретацию этой повести ещё и как травестирование священного таинства евхаристии (нос в хлебе, лицо без носа гладко, как блин, нос, выходящий из кондитерской, нос как человек), то выбор даты также нельзя считать случайным. 
Удвоенной является и сюжетная линия, и словесная динамика произведения. Цирюльник Иван Яковлевич как-то утром находит в хлебе нос коллежского асессора Ковалева, которого он брил каждую среду и воскресенье, и с недоумением замечает: „Черт его знает, как это сделалось". Затем описан проснувшийся коллежский асессор Ковалёв, который „к величайшему изумлению, увидел, что у него вместо носа совершенно гладкое место" и который при этом произносит те же, правда, усиленные (удвоенные) фразы: „Черт знает что, какая дрянь”, и: „Черт его знает, как это сделалось” (Гоголь, 1977/3, 40-63) Два начала показывают и два вида освободившегося носа: один выглядит как «реальный» и появляется в хлебе, кармане и тряпке, а второй приобретает человеческий облик и становится государственным чиновником.

Иван Яковлевич безуспешно пытается выбросить нос в реку его останавливает квартальный надзиратель, так что в воде остаётся только отражение. С другой стороны, в погоне за потерянным носом Ковалёв заходит в кондитерскую на Невском: он „робко подошел к зеркалу и взглянул [...] хотя бы уже что-нибудь было вместо носа, а то ничего!”. Затем перед кондитерской „произошло явление неизъяснимое”: из кареты „выпрыгнул, согнувшись, господин в мундире”, в котором он узнал собственный нос.

Антропорморфизация и обособление носа, имея ввиду типологию зеркальности М. Вайскопфа, можно истолковать как воплощение „идеи литературного героя”, так что нос становится его вторым „я”. Поскольку Ковалёв мечтает о более высоком чине (ср. и удвоение: в повести у героя то звание чиновника - „коллежский асессор”, то воинское - „майор”), появление носа в роли статского советника связано с реализацией скрытой мечты. Так что здесь можно говорить и о своеобразном исполнении желания, как в сказке, с той разницей, что в вымышленной зеркальной реальности исполнение затрагивает не Ковалёва, а его нос. Поскольку зеркало отражает симметричное пространство, противоположное действиям, здесь искажённый взгляд передаёт перевёрнутый мир: нос - это человек, а человек без носа не гражданин (,без носа человек - черт знает что: птица не

\footnotetext{
${ }^{8}$ Здесь и далее повесть Гоголя цитируется по этому изданию.
} 
птица, гражданин не гражданин, - просто возьми да и вышвырни за окошко!"), то есть, следовательно, и не человек. Если опереться на интерпретацию М.М. Бахтина, согласно которому в гротескном мире наоборот нос определяется как фаллический символ (Бахтин, 1975, 484-493) ${ }^{9}$, то тогда исчезновение носа означает для героя не только общественное унижение, но и утрату половой сущности. В пользу этого говорит и тот эпизод повести, в котором высказываются сомнения Ковалёва, что „штаб-офицерша Подточина, которая желала, чтобы он женился на ее дочери”, наняла „колдовок-баб” лишить его носа.

И, однако же, как часто бывает у Гоголя, рациональные объяснения необычных событий совершенно отсутствуют. Вместо них рассказчик предлагает пародийный автореференциальный комментарий о том, как в его повести „есть много неправдоподобного”: „Теперь только, по соображении всего, видим, что в ней есть много неправдоподобного (...) но что страннее, что непонятнее всего, - это то, как авторы могут брать подобные сюжеты”. Его словесная игра, которая и сама участвует в создании необычной вымышленной действительности, здесь, однако, не заканчивается. В последних строках автор указывает, что в рассказанном всё же есть „некоторая доля истины”, потому что ,а всё, однако же, как поразмыслишь, во всём этом, право, есть что-то. Кто что ни говори, а подобные происшествия бывают на свете, - редко, но бывают".

Однако независимо от туманности или скрытости мотива происходящего можно догадаться, что всё случившееся было делом рук самого черта. А именно, во всей повести в манере гоголевского сказа постоянно встречаются выражения типа „черт знает что”, „черт его знает”, „чёрт так хотел” и т.д. И сам главный герой объясняет свою судьбу словами ,Чёрт хотел подшутить надо мною”, а немного позже добавляет: „Каким же образом, какими судьбами это приключилось? Только чёрт разберёт это”.

Важная особенность гоголевской прозы в том, что именно те предметы, которые являются носителями главной идеи вымышленного

${ }^{9}$ Ср. также исследования И.Д. Ермакова (Ермаков, 1999) и И.П. Смирнова (Смирнов, 1994). 
мира, выражают её, как раз и используются как формообразующий фактор. В данном случае зеркало и его отражение, вместе с чертом, который забавляется с миром в зеркале, определяют мотивационный, структурный и смысловой планы повести. С другой стороны, нужно отметить, что демонические герои и их действия у Гоголя не просто воплощают зло, а предвещают внутреннюю борьбу человека против тёмных сил.

Итак, двойственность художественного мира гоголевских повестей -Старосветские помещики, Страшная месть и Нос отражена в плане жанра, в плане речевой динамики, в пространственно-временном плане, а также и в мотивировке литературных героев. Удвоение действительности и существ, которые в повествовательном мире Гоголя часто передаются с помощью зеркала, двойника, сна или видения, показывает, в сущности, неудобство, которое чувствует человек, когда сталкивается не только со своим „я”, но и с попытками объяснить себя через другого, увидеть себя в чужой душе. Символическое выражение этого внутреннего состояния, как правило, происходит подобным же образом, с помощью сходных понятий, представлений и зеркальных, двойных структур, которые целенаправленно связывают воедино идею и её реализацию. Начальный страх, воплощённый в художественном изображении черта, удвоенного мира и существ, в неделимых значимых действиях героев и автора постепенно приводит к победе над злом и грехом, а в конечном итоге - к своеобразному внутреннему просветлению и преображению. Познание природы собственной души и, в соответствии с этим, отношение к Другому, можно найти только в действиях, в художественном творчестве. Поэтому победа над чертом, чужим миром и злом - эстетическая и нравственная одновременно.

Соотнесенность между удвоенными формами и их семантической функцией в поэтике Гоголя обнаруживает также общеизвестный парадокс исторической поэтики: история в своей сути подразумевает изменчивость и неповторимость явления, тогда как поэтика имеет дело с устойчивыми структурами и нормами (Holquist 1990: 109). В данном анализе повестей Гоголя показано, что изменчивость преимущественно касается внешней структуры жанра, а внутренняя функция, т.е. идейность жанра оказывается постоянной. Литературное 
произведение, как уже отмечено, отличается системностью, и поэтому изменчивость или постоянность его формы напрямую связаны с конструктивной функцией и идейной направленностью этой формы. Ю.М. Тынянов говорит о том, что эволюцию жанра характеризует смешение разнообразных приёмов, т.е. конструктивных принципов, а суть новой конструкции лежит в новом использовании старых приёмов, т.е. в их новом конструктивном значении (Тынянов, 1977, 271). В этом сложном процессе главную роль исполняет взаимодействие формы и семантики, причем воспроизведение жанра (в данном случае идиллии, героической поэмы и паремии) основывается на „культурно-исторической телепатии”, т.е. на „памяти жанра”.

Для понимания поэтики Гоголя очень важен и вопрос соотнесенности и взаимодействия конструктивных принципов разных искусств: живописи, скульптуры и театра. Неподвижность художественного пространства и времени его повестей соответствует неподвижности двумерного изображения действительности, как в изобразительном искусстве или в зеркальном отражении. Конструктивный принцип, образующий удвоенные структуры гоголевских повестей (сновидение/реальность, былое/настоящее, здешний/нездешний и т.д.), заимствованный из живописи, исполняет, таким образом, и формальную, и семантическую жанровую функцию. Повествовательная действительность не соответствует настоящей реальности, она деформирована благодаря смешению приемов разнообразных искусств. Одновременно, неподвижность семантики художественного мира получает внутреннюю динамику с помощью сюжетной конструкции, воспроизводя, таким образом, старинный, „забытый” жанр.

\section{Литература}

Анненский, И. (1979). Книги отражений. Москва: Наука.

Бахтин, М.М. (1963). Проблемы поэтики Достоевского. Москва: Художественная литература.

Бахтин, М.М. (1975). Вопросы литературы и эстетики. Москва: Художественная литература.

Бахтин, М.М. (2002). Собрание сочинений в 8 томах, т. 6. Москва: Языки славянских культур. 
Белый, А. (1934). Мастерство Гоголя. Москва-Ленинград: Государственное издательство художественной литературы.

Бочаров, С.Г. (2012). Генетическая память литературы. Москва: Российский государствнный гуманитарный университет.

Вайскопф, М. (2002). Сюжет Гоголя. Морфология. Идеология. Контекст. Москва: Российский государствнный гуманитарный университет.

Вайскопф, М. (2003). Птиия-тройка и колесница души. Москва: Новое литературнное обозрение.

Виноградов, В.В. (1963). Стилистика. Теория поэтической речи. Москва: АН СССР.

Виролайнен, М. (2003). Речь и молчание: Сюжеты и мифы русской словесности. Санкт Петербург: Амфора.

Гиппиус, В.В. (1966). Творческий путь Гоголя // От Пушкина до Блока. Москва-Ленинград: Наука.

Гоголь, Н.В. (1976-1979). Собрание сочинений в 7 томах. Москва: Художественная литература.

Ермаков, И.Д. (1999). Психоанализ литературы. Пушкин. Гоголь. Достоевский. Москва: Новое литературнное обозрение.

Јовановић, М. (1995). Приповетке Николаја Гогоља или посрамљивање Ђавола. Београд: Српска књижевна задруга.

Лотман, Ю.М. (1988). В школе поэтического слова. Пушкин. Лермонтов. Гоголь. Москва: Просвещение.

Манн, Ю.В. (1996). Поэтика Гоголя. Вариациии к теме. Москва: Соda.

Мережковский, Д. (1906). Гоголь и черт. Москва: Скорпион.

Ремизов, А.М. (1954). Огонь вещей. Сны и предсонье. Париж: Оплешник.

Смирнов, И.П. (1994). Психодиахронологика. Психоистория русской литературы от романтизма до наших дней. Москва: Новое литературнное обозрение.

Тынянов, Ю.Н. (1977). Поэтика. История литературы. Кино. Москва: Наука.

Günther, H. (1968). Das Groteske bei N. V. Gogol'. Formen und Funktionen. München: Sagner.

Holquist, M. (1990). Dialogism: Bakhtin and his World. London-New York: Routledge. Nabokov, V. (1944). Gogol. New York: New Directions. 